\begin{abstract}
"Two suspects are taken into custody and separated. The district attorney is certain that they are guilty of a specific crime, but he does not have adequate evidence to convict them at a trial. He points out to each prisoner that each has two alternatives: to confess to the crime the police are sure they have done, or not to confess. If they both do not confess, then the district attorney states he will book them on some very minor trumped-up charge such as petty larceny and illegal possession of a weapon, and they will both receive minor punishment; if they both confess they will be prosecuted, but he will recommend less than the most severe sentence; but if one confesses and the other does not, then the confessor will receive lenient treatment for turning state's evidence whereas the latter will get "the book" slapped at him." (Luce \& Raiffa, 1957, p. 95).

The "Prisoner's Dilemma" - to co-operate or to defect, to trust or to distrust, to sacrifice immediate profit for the sake of long-run gain-is a situation which occurs time and again in the marketplace, in the smoke-filled rooms of a political convention, on Wall Street, and on Capitol Hill. Games of strategy have been devised for experimental study of this dilemma. But "pure" game theory assumes completely rational players, and as every reader will attest, human beings can be anything but rational. Often players will base their strategies on factors other than the rules of the game. This paper describes an investigation of three of these factors which may affect cooperation in Prisoner's Dilemma games.
\end{abstract}

\title{
FACTORS AFFECTING CO-OPERATION IN THE PRISONER'S DILEMMA
}

by Lester B. Lave

Carnegie Institute of Technology ${ }^{1}$

\section{INTRODUCTION}

$T^{\prime}$ HE Prisoner's Dilemma is a 2-person situation in which each player must forsake the possibility of maximizing his own (short-run) profit to enjoy the greatest payoff (maximize long-run profit). An example is the decision of a duopolist to maintain the high price of his rival. Either firm would gain a considerable short-run advantage by cutting price. The inducement to cut price becomes even stronger after the other firm has done so, but if both firms resort to pricecutting, the profits of both will fall.

${ }^{1}$ This investigation was supported by U. S. Public Health Service Grant MH 07410 from the National Institute of Mental Health. The research was conducted at Harvard University in the spring of 1963. The following people contributed to this work, although they share no responsibility for errors: Arthur Carlson, Walter Reitman, Robert Bishop, Lawrence Fouraker, Renee Reitman, Suzanne Rosenfeld, Ruth Westheimer, and Judy Rice.
This situation is illustrated below in Figure 1. Here Firm A must decide whether to choose strategy 1 (maintain a high price) or strategy 2 (cut price); Firm B must also choose between these alternatives. The consequences of these actions are noted in the matrix. If both firms choose to maintain their prices (strategy 1), both win 3 . If one firm decides to cut price (strategy 2) while the other maintains price (strategy 1), the former firm will make 10 while the latter firm loses 5. Finally, if both decide to cut price, both lose 3 .

In an appropriate institutional setting this situation can form the basis of many economic conflicts from duopoly problems to bargaining over tariffs (Lave, 1962). It can also serve as a rather general model of conflict for the psychologist. The situation has been abstracted into a game of strategy for experimental treatment. These experiments have shown the Prisoner's Dilemma 


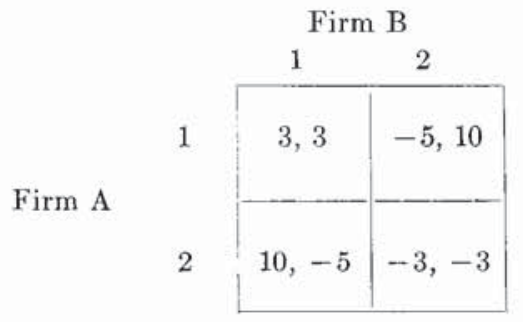

Fig. 1. The Prisoner's Dilemma (Matrix 5). The first payoff in each square goes to Firm A, the second to Firm B.

to be an extremely delicate situation in which apparently subtle changes in conditions give rise to wide differences in the collusion or competition found. Although it seems clear that a large number of elements are involved in the decision of a subject about whether or not to establish co-operation, except for Deutsch (1962) little work has been reported that has specifically set out to find what these elements are. The present series of experiments attempts to investigate three possible factors that are both important and easily amenable to experimental treatment.

\section{Three factors affecting co-operation}

Number of trials. The first critical element in producing co-operation in the Prisoner's Dilemma is the number of trials the game will be repeated. With an unknown rival and a 1-trial game, it is difficult to imagine the wisdom of choosing strategy 1 . The single-trial situation eliminates both the possibility of future co-operation and the possibility of punishing a rival for noncooperative action in the one trial.

The number of trials to be played can make the matrix more dramatic and cooperation more practical. Consider two games where the payoffs in the second are $n$ times those in the first. The second game is to be played for a single trial while the first game will be played for $n$ trials. The two games are equivalent in the formal sense that the amount of money each player can win is equal in both games (or the expected values of the two games have the same range across different opponents). However, the games are quite different with respect to negotiating co-operation and the division of payoffs. The expected values of the two games are not equal for a given rival, since certain forms of behavior can induce cooperation or competition. When a game is iterated, it is possible to display behavior that induces or stifles co-operation; it is possible to use the choices in the game to communicate with each other. The tacit, rudimentary form of this communication takes time, no matter how dramatic the matrix nor how well disposed the two players. With an unknown rival, a single trial can never serve to establish co-operation; there is not time for a response to one's choice. Before he makes his choice, a player cannot know that his rival seems willing to co-operate. Moreover, in order to gain cooperation, there should be sufficient trials so that the risk of loss, of unsuccessful negotiation, seems small in comparison with the possible gain. Thus, the longer the game, the more likely it is that a stable co-operation solution is achieved.

Earlier work (Lave, 1960) conjectured that, within a narrowly defined group, the expected value of attempting co-operation (choosing strategy 1) exceeded that of doing nothing (choosing strategy 2) when the number of trials, $n$, was large enough so that $k(d-b)<n(a-d)$ (see Figure 2).

\begin{tabular}{ccc|c|} 
& & \multicolumn{2}{c}{ Player B } \\
& & 1 & 2 \\
\cline { 2 - 4 } & 1 & $a, a^{\prime}$ & $b, c^{\prime}$ \\
Player A & & & \\
& 2 & $c, b^{\prime}$ & $d, d^{\prime}$ \\
\hline
\end{tabular}

Again, the first payoff in each square goes to Player A, the second to Player B.

\begin{tabular}{cccrcc} 
& Payoffs: & $a$ & \multicolumn{1}{c}{$b$} & $c$ & $d$ \\
Matrix : & 1 & 3 & -100 & 4 & -3 \\
& 2 & 3 & -75 & 4 & -3 \\
3 & 3 & -50 & 4 & -3 \\
& 4 & 3 & -5 & 4 & -3 \\
5 & 3 & -5 & 10 & -3 \\
6 & $2,5^{*}$ & -5 & 10 & -3
\end{tabular}

FIG. 2. Matrices Used in Experiments. Note: Figure 1 illustrates Matrix 5.

* If both players choose strategy 1 in Matrix 6 , Player A receives a payoff of 2 while Player B receives a payoff of 5 . 
As argued below, $d-b$ is the loss for an unsuccessful attempt to co-operate, while $a-d$ is the difference between the payoffs for co-operating and for competing with the rival. The parameter that summarizes the subject population is $k$ and was found to be about three for a population of Reed College undergraduates. Since the subjects of the present experiments are also undergraduates of comparable intelligence, we presume $k$ to take on a value of about three for these experiments.

Payoffs. The second critical element affecting co-operation is conjectured to be the specific numerical entries in the matrix relative to one another. It seems likely that, as the entries vary, co-operation can be made easier to achieve initially, easier to stabilize on, etc. The six matrices used in these experiments are described in Figure 2. In particular, we might hypothesize that the larger $b$ is with respect to $a$, the more difficult it will be for a subject to decide to attempt co-operation. Picture a subject deciding whether to show that he wishes to co-operate by choosing strategy 1 when his rival has not yet shown any signs of being co-operative. This player is almost surely faced with at least one trial at payoff $b$, the lowest payoff in the matrix. (The larger this loss, the more reluctant a player will be to attempt co-operation.)

Second, we might expect that the larger $c$ is with respect to $a$, the greater will be the pull away from co-operation and the less likely it will be that a pair will settle on stable co-operation. The payoff $c$ is the value of "double-crossing" one's partner once co-operation at 1,1 has been achieved.

Third, we might expect that the smaller $d$ is with respect to $a$, the more likely it would be that a subject will attempt to achieve co-operation at 1,1 . From the way the matrix is defined, $a$ is the reward for cooperation while $d$ is the penalty for nonco-operation after both players have evolved a stable position at either co-operation or competition. The factor $a-d$ then measures the incentive to establish co-operation. The incentives leading to co-operation can be summarized in the hypothesis stated above, that subjects will attempt to co-operate when the number of trials is large enough so that $3(d-b)<n(a-d)$. For these experiments, $d$ was never varied.

Finally, we might expect that a move toward asymmetric payoffs as shown in matrix 6 will strongly affect co-operative behavior. When players co-operate in matrix 6 , Player A receives only 2 while Player B receives 5 . It was hypothesized that such an asymmetry would disrupt the game and greatly reduce the amount of co-operation achieved. Players would be attempting to settle the question of how payoffs should be divided as well as whether they wanted to achieve co-operation. ${ }^{2}$ Since players are not permitted to talk to each other, they can only communicate by their choices in the game. There is a necessary ambiguity under these conditions when a player $\mathrm{A}$ chooses strategy 2 in order to achieve more equal payoffs: Is he giving up co-operation for all time or simply modifying the pattern under which he is willing to co-operate? (Since a player's choices are the way in which he indicates whether a distribution of the payoffs is satisfactory, it is possible that the bargaining process might never terminate. Until bargaining terminates, there is no compelling reason to predict that subjects will go to a Pareto optimal point [Bishop, 1960].)

Schelling has conjectured that there will be a tendency for simple, obvious, probably symmetric solutions to occur in games, especially as the problems of co-ordination are emphasized and those of bargaining played down $(1960$, p. 54). He has also conjectured that the assumption of symmetry is not always a good one in bargaining situations $(1960$, p. 267). In the case of the asymmetric matrix, the former conjecture might be

\footnotetext{
${ }^{2}$ In a summary of results from small-group experiments, Berelson and Steiner (1964, p. 353) note that "At least in American studies, and on tasks requiring collaborative activity, co-operative groups are more cohesive and more personally satisfying than internally competitive ones, and their performance is more homogeneous and usually more effective." Applied to matrix 6 the proposition might be interpreted to say that the asymmetry has emphasized the conflict between players to the detriment of the goal of the group to form a coalition against the experimenter.
} 
formalized as the hypothesis that subjects will probably fall into co-operating at 1,1 and disregard the asymmetry or perhaps find some equally simple way which would yield symmetric payoffs. The latter conjecture might be formalized as the hypothesis that subjects will not insist on equal payoffs if it seems likely that doing so will cost a fair amount of money.

The other player. The third critical factor involves the characteristics of the subject a player is paired with. In order to find the extent of co-operation, some of these experiments were run with subjects paired with each other. But a more interesting and time-saving procedure involves running a subject against some fixed behavior pattern played by a stooge. Such planned behavior patterns allow intensive investigation of the power of certain strategies to induce collusion or the hope of collusion in a subject.

Four behavior patterns were distilled from earlier experiments. To aid in remembering these patterns, they were given colorful names. The first pattern, Stalin, involves always playing strategy 2 (the nonco-operative strategy) no matter what the subject plays. Khrushchev played strategy 2 constantly, except for an occasional sally over to strategy 1. The third stooge, Coolidge, played strategy 1 only after the subject had played strategy 1 four times and was choosing it a fifth time. The final stooge was Gandhi, who always chose strategy 1.

While these stooges are archetypes of subjects' behavior patterns, it is possible to cite a logical, consistent explanation for each pattern. Stalin has a utility function that indicates an enormous loss if he should ever play strategy 1 while the other player chooses strategy 2. His loss would be so high that he is willing to forego the possibility of earning money by co-operating. A player choosing a Stalin pattern believes his opponent is both powerful and malevolent, and so he protects himself against the worst. He chooses a strategy to minimize his maximum possible loss: the minimax strategy.

Khrushchev is a slightly more flexible Stalin who is taking advantage of the knowledge he obtains from his opponent's reactions. He is not especially concerned about being double-crossed, he is only concerned with maximizing his relative payoff, i.e., his payoff minus his opponent's payoff. It seems likely that after a very few attempts, the Khrushchev pattern can involve too many strategy 1's and come out with a lower absolute (or even relative) payoff than Stalin.

Coolidge is simply an extremely cautious player. He does want to co-operate and make money, but he is suspicious of his partner until the partner has shown good intentions. The Coolidge pattern defines good intentions as willingness to go almost bankrupt in the attempt to signal co-operation.

The last pattern, Gandhi, was particularly prevalent among Harvard undergraduates. They analyzed the game and concluded that the only way the pair could make money was by co-operating. This immediately led them to the conclusion that they should never play anything except strategy 1 . These subjects would have played only strategy 1's throughout, but they were slightly suspicious of the experimental situation and so concluded, in those cases where they were not answered with strategy 1's, that the game was somehow rigged (which was not always so).

\section{Three conjectures concerning subjects' be- havior}

There are three further conjectures concerning subjects' behavior that might be mentioned since some small amount of evidence can be brought to bear on them. (1) A subject's experience in the game is likely to influence the way he plays in the future. In a few cases a second game was run at the conclusion of the first game to examine this assumption. (2) Different subjects should exhibit different behavior patterns in the game. A first approach to measuring these differences involves using subjects from three universities and conjecturing that the population within each university is homogeneous while that between universities is different. (3) A subject's behavior should change if he knows the exact number of trials in the game. Luce and Raiffa (19.57) demonstrate in a proof by backward induction that no matter how long the game, if subjects are 
told the number of trials, collusion is not as good for one player as choosing strategy 2; collusion is said to be dominated. This process of fixing on strategy 2 for the last trial and extending the logic back to the first trial has been found unlikely to occur in practice beyond a trial or two from the end. One can avoid the proof by backward induction by a simple change in the conditions of the game: tell players that the game will end after trial $n$ with probability $p$. Both ways of ending the game are used in these experiments, and an attempt is made to evaluate further the practical importance of the Luce-Raiffa proof.

\section{Comments on experimental methodology}

Two variations in procedure which have been incorporated into these experiments should be commented upon, since there may be questions about their effect and desirability. The first involves paying subjects substantial sums of money for the game so that their earnings depend on their winnings in the game. Evidence presented earlier (Lave, 1960) showed that there were substantial differences in behavior depending on whether subjects were actually paid or were merely told to "imagine that the money made a difference to them." In the present series of experiments, subjects often questioned the experimenters on the subject of money and apparently small differences in payoff were noticed. Many subjects caught small errors in the payoffs and wanted them rectified immediately. There was also much concern over the total payoff.

The second concerns some reported experiments (Fouraker \& Siegel, 1963; Siegel \& Fouraker, 1960; Suppes \& Carlsmith, 1962) which have instructed subjects to behave as if each were a large oligopolistic firm, a major nation in world affairs, or some such. A game such as the Prisoner's Dilemma might be set up in terms of prices set, quantities sold, people killed, etc. Such a setup tends to give the experiment an air of the parlor game: the subject cannot fully comprehend what he is to do, whom he is to please, or what he is to maximize. But a more serious difficulty might result. The subject is told to behave as if he were the "President of U.S. Steel" or the "President of the United States." Such an injunction can hardly be followed except through a subject's individual (almost certainly naive) conception of the way he thinks Roger Blough or Lyndon Johnson behaves. Thus, a subject behaves as he imagines someone else acts and not the way he himself would act. The result can only be a tendency toward confused behavior with the subject never sure what is expected of him and playing according to inconsistent principles. If one uses college sophomores as subjects, one should at least get the behavior of college sophomores, not the behavior that college sophomores imagine is typical of Lyndon Johnson.

One illustration of the failure, when using college students, to understand that they are motivated and behave as college students is contained in Siegel and Fouraker (1960, p. 100): "In the present series of experiments, only one pair of subjects failed to reach a contract. This statistic is startling, when considered in the light of the frequency with which negotiations are broken off under other circumstances. Apparently the disruptive forces which contribute to the rupture of some negotiations were at least partially controlled in our sessions." Since they were paying their subjects about $\$ .5$ for less than two hours of gaming, an alternative explanation might note that the levels of payoffs were so high that, with a wide range of acceptable payoffs, there was only the matter of somehow dividing the money. In their terminology, the subject's level of aspiration was below the range of possible payoffs.

\section{EXPERIMENTS: METHOD}

Twelve series of experiments were conducted in the spring of 1963 using undergraduates of Harvard University, Massachusetts Institute of Technology, and Northeastern University. Subjects were hired through advertisements in the school newspapers. The advertisements stated that subjects would take part in a bargaining experiment that had reference to international politics and that pay would depend on per- 
formance in the game. Subjects were given a standard instruction sheet with appropriate changes for the different matrices used and an appended paragraph when they were to play more than a single game.

The instruction sheet informed subjects that they were to play a bargaining game and that the $\$ 5$ which they had been given ( $\$ 4$ was used in games with types 4,5 , and 6 matrices, see below) was theirs, but had to be used to cover any losses incurred during the game. The only goal mentioned in the instructions enjoined subjects to maximize their winnings since everything they won would be part of their earnings. The instruction sheet went on to present the matrix to be used, to state the number of trials the game would be played, and to explain the numbers in the matrix so that subjects would know the payoffs for each combination of strategies in the game. After a subject had made his choice, he was given a slip of paper stating: "You chose strategy ( ) while the other player chose strategy ( ). Thus you win (or lose) ( ) $\&$ while the other player wins (or loses) ( ) c." He was then paid or charged the appropriate amount. Subjects recorded their strategy choices on a sheet which had a place for recording, if they chose, the strategy choices of their rival. Subjects were asked to write a brief explanation of each choice they made.

As in a previous game (Lave, 1962) when the number of trials was large, subjects were allowed to fill out a superstrategy telling how they would behave for the remainder of the game. Such a procedure became available only after a large number of trials. When it became apparent that almost all subjects wanted to fill out this superstrategy, it was suggested that everyone write it out. In only eight cases out of 84 (9.5 per cent) did subjects wish to continue playing and prefer not to write a superstrategy.

Table 1 lists the number of subjects taking part in each of the experiments performed. These experiments were performed in twelve sessions lasting approximately two hours each. Every attempt was made to prevent the earlier experiments from contaminating those that came later: One school was taken
TABLE 1

Nember of Subjects in Each Situation

\begin{tabular}{|c|c|c|c|c|c|}
\hline \multirow{2}{*}{$\begin{array}{c}\text { Number of Trials } \\
\text { by Stooges }\end{array}$} & \multicolumn{5}{|c|}{ Matrix } \\
\hline & $1-2$ & 3 & 4 & 5 & 6 \\
\hline 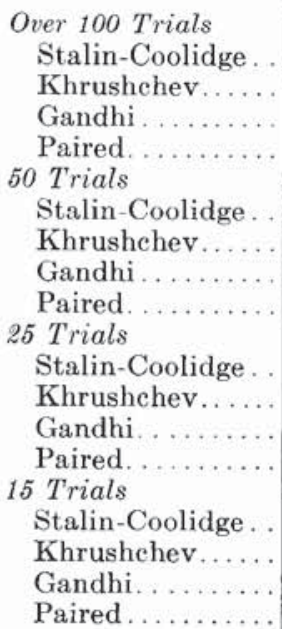 & 14 & $\begin{array}{c}1,16^{*} \\
16^{*} \\
32,16 \dagger\end{array}$ & $\begin{array}{r}14 \\
9 \\
5 \\
6 \\
10\end{array}$ & $\begin{array}{l}4 \\
6\end{array}$ & 16 \\
\hline
\end{tabular}

* Second game.

† Northeastern University subjects.

at a time, subjects were asked not to tell others about the game, and not more than four weeks elapsed between the beginning and end of experiments at one school or more than seven weeks between the beginning and end of all experiments. There was no evidence of contamination.

\section{RESULTS}

The first factor hypothesized to affect co-operation, the number of trials in the game, can be tested in matrices 1-2, 3, and 4 . (A preliminary analysis revealed that behavior in the first two matrices was the same and so they were aggregated throughout these analyses.) Table 2 shows the percentage of players attempting co-operation in games using these matrices when the number of trials was varied from over 100 to 50,25 , and 15 . It was hypothesized that players would attempt co-operation if the number of trials were such that $3(b-d)<$ $n(a-d)$ (see Figure 2). Nine tests are presented in the table along with the percentage of players in each experiment who contra- 
TABLE 2

\begin{tabular}{|c|c|c|c|c|c|c|c|}
\hline & & Player & is Аттемн & PTING & CO-OPEI & ATION & \\
\hline & $\begin{array}{l}\text { Ma- } \\
\text { trix }\end{array}$ & $\begin{array}{l}\text { No. } \\
\text { Trials }\end{array}$ & $\begin{array}{l}\text { Dummy } \\
\text { or Pairs }\end{array}$ & $\begin{array}{r}\text { Perce } \\
\text { Pl } \\
\text { Ch } \\
\text { One } \\
\text { Stra }\end{array}$ & $\begin{array}{l}\text { ntage of } \\
\text { ayers } \\
\text { oosing } \\
\text { or More } \\
\text { tegy 1's }\end{array}$ & $\begin{array}{c} \\
\text { Criti- } \\
\text { cal } \\
\text { No. of } \\
\text { Trials }\end{array}$ & $\begin{array}{c}\text { Per- } \\
\text { centage } \\
\text { of } \\
\text { Players } \\
\text { Deviat- } \\
\text { ing } \\
\text { From } \\
\text { Hypo- }\end{array}$ \\
\hline & $1-2$ & Over 100 & Coolidge & 85.7 & $(12 / 14)$ & 45 & 14.3 \\
\hline & 3 & Over 100 & Pairs & 100 & $(28 / 28)$ & 24 & 0 \\
\hline & 3 & 25 & Stalin & 66.7 & $(4 / 6)$ & 24 & 33.3 \\
\hline & 3 & 25 & Pairs & 85.7 & $(12 / 14)$ & 24 & 14.3 \\
\hline & 3 & 15 & Pairs & 50 & $(3 / 6)$ & 24 & 50 \\
\hline & 4 & Over 100 & Pairs & 100 & $(28 / 28)$ & 1 & 0 \\
\hline & 4 & 50 & Stalin & 100 & $(9 / 9)$ & 1 & 0 \\
\hline & 4 & 50 & Pairs & 100 & $(10 / 10)$ & 1 & 0 \\
\hline & 4 & 15 & Pairs & 100 & $(6 / 6)$ & 1 & 0 \\
\hline
\end{tabular}

dicted the hypothesis. The hypothesis is substantiated in five cases, only 14 per cent of the players deviated from it in another two cases, and the two exceptions show deviations of 33 per cent and 50 per cent. In all, only nine players out of 101 contradicted the hypothesis. However, these tests were generally not near the critical area. The data must be conceived to be generally in favor of the hypothesis, although they do not prove it.

In examining the effect of entries in the matrix on co-operation (factor 2), we hypothesized that the smaller $b$, the more attempts would be made toward co-operation and the smaller $c$, the more stable would be co-operation once it had been achieved. In going from matrix 1 to matrix 4 the size of $b$ is reduced successively from -100 to -5 , while other factors are held constant. Table 2 shows the percentage of subjects attempting co-operation (defined as choosing one or more strategy 1's) in these matrices. In the games with more than 100 trials, the percentage of subjects attempting co-operation increases from 85.7 per cent to 100 per cent in moving from matrix 1-2 to matrix 4 . The 15-trial games also support the hypothesis, although none of the tests seem to be sensitive ones.

Figure 3 presents a comparison of matrices 4 and 5 where $c$ was changed from 4 to 10 . The matrix shows that, as hypothesized, co-operation is more unstable in matrix 5, although the effect is not very large. (Note that all pairs arrived at co-operation at least momentarily and that any deviation from complete co-operation is due to instability.) The apparent difference is further diminished by the fact that one pair gained co-operation in matrix 5 by alternately double-crossing, i.e., 1,$2 ; 2,1 ; 1,2: \ldots$. Thus, the curve for matrix 5 is higher than shown. A purer test of this question is presented below in connection with the Gandhi stooge.

It was hypothesized that asymmetry would cause a drop in the percentage of pairs co-operating since players would spend effort worrying about the way payoffs should be split. In games with 50 trials, there was 57.5 per cent co-operation in matrix 5 and 50 per cent co-operation in matrix 6 . Subjects did spend time trying to indicate what were acceptable splits, and three patterns of co-operation emerged. In the first, subjects stayed with the conventional 1, 1 and forgot asymmetries in the payoffs; only one pair was satisfied with this solution. In the second pattern, subjects alternately double-crossed each other: 1,$2 ; 2,1 ; 1,2 ; \ldots$ to get an expected value of 2 and $1 / 2$ cents per trial; two pairs found this second pattern an acceptable solution. Finally, one pair settled on the optimal way of gaining equal payoffs: they played five trials at 1,1 and then played 2, 1 for the sixth trial to achieve an expected value of 3 and $1 / 3$ cents per trial. The outstanding feature of the asymmetric game is that subjects failed to understand each

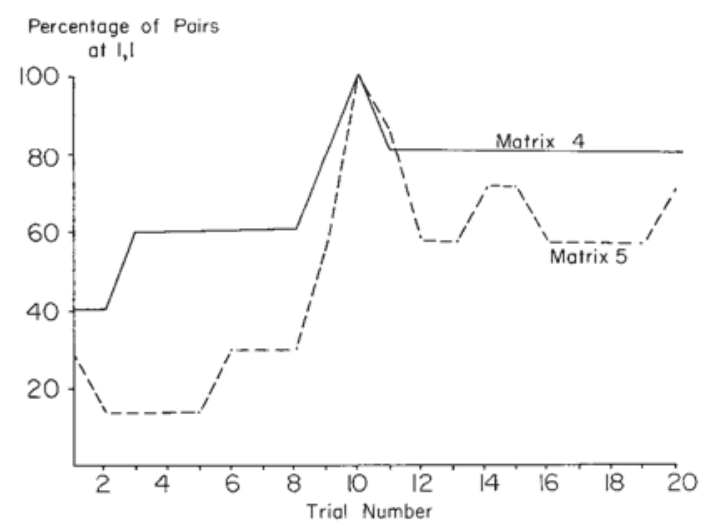

FIG. 3. Effect of Increasing the Incentive to Double-Cross (Matrices 4 and 5, 50 Trials). 
other's signals and had the greatest difficulty settling on some stable form of co-operation.

The fixed behavior patterns (factor 3) provided more systematic evidence on reactions of players to given strategies. The Stalin dummy can be used to give some idea of the number of strategy 1's subjects were willing to choose when faced with a partner who is either too stupid or too malevolent ever to choose a strategy 1 . (The Coolidge pattern is identical with the Stalin pattern until the fifth choice of strategy 1 . The patterns are not analyzed separately here.)

Table 3 presents a comparison between the reactions of subjects to such a stupid or malevolent partner for two matrices: 1-2 and 4 . In order to hold constant the attractiveness of co-operation, matrices 1-2 were run with more than 100 trials while matrix 4 was run with 50 trials (thus, they should be strictly comparable so far as the number of trials is concerned if the previous hypothesis about the affect of the number of trials is correct). The median number of strategy 1's chosen is the same, four, for both matrices 1-2 and matrix 4 . The principal difference is that subjects are strung out toward the bottom in the former matrix. Thus, the median amount of co-operative behavior toward a stupid player was the same in both the high-loss matrices (1 and 2) and in the low-loss matrix (4).

The table also presents a comparison between the reactions of players to different types of given strategies, holding other variables constant. Within the context of matrix 4 in a 50 -trial game, subjects reacted to Stalin, Khrushchev, and Gandhi. The goal of the Khrushchev pattern is to maximize payoff relative to the rival's. Therefore, when his opponent starts to write him off as nonco-operative, the Khrushchev stooge plays a strategy 1 to stir his rival's hopes. Figure 4 shows the percentage of players choosing strategy 1 in a second game when one group is confronted with Stalin and another with Khrushchev. Note that players react strongly to Khrushchev's hint that he may be willing to co-operate. Figure 5 shows a comparison between these two behavior patterns in matrix 4 with a 50 -trial game. Again, Khrushchev appears to stimulate his rival strongly to play strategy 1 . However, by the fourth time Khrushchev chooses strategy 1 , his rival refuses to react at all. Table 3 shows that the mean response for the Khrushehev pattern is about three higher than for the Stalin pattern, thus both making a case for Khrushchev's effectiveness and pointing out that after the second time he loses this effectiveness.

If the rationale behind the Gandhi pattern strategy were correct, we would expect to find all subjects co-operating with the stooge within a short time. Figure 6 shows the percentage of players choosing strategy 1 in matrices 4 and 5 in 50 -trial games. Note that the curves reach an initial high and then decline as players discover that their partner would choose only strategy 1 . As a matter of

TABLE 3

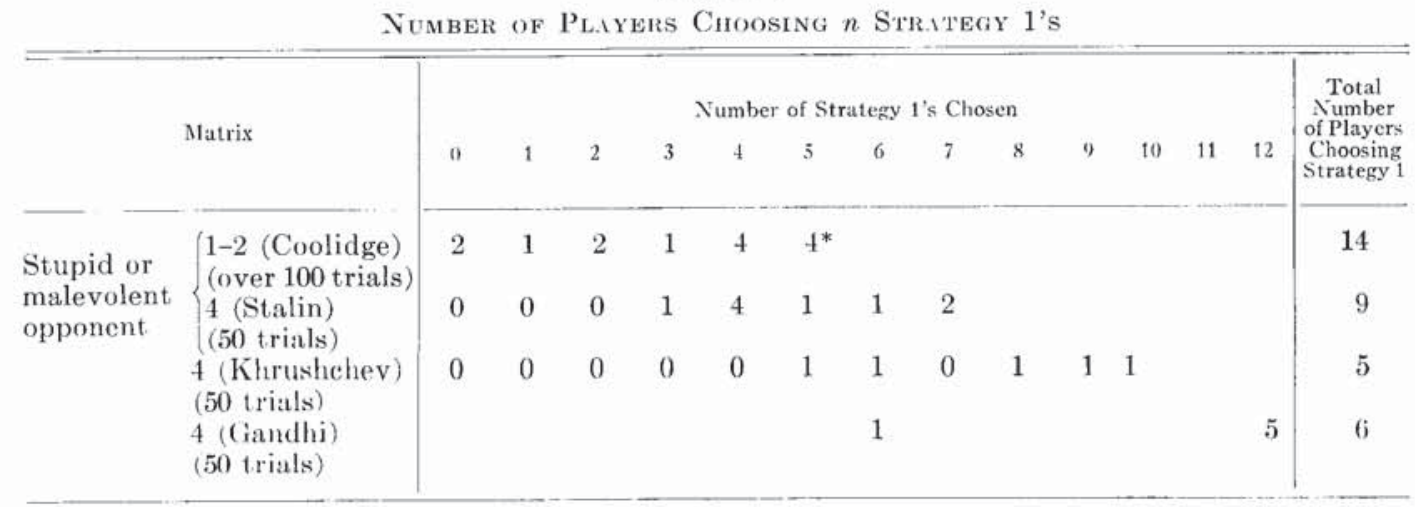

Stalin average number of 1 's $=4.89$.

Khruschev average number of 1's $=7.6$.

* Number of players choosing 5 or more strategy 1's. 
34

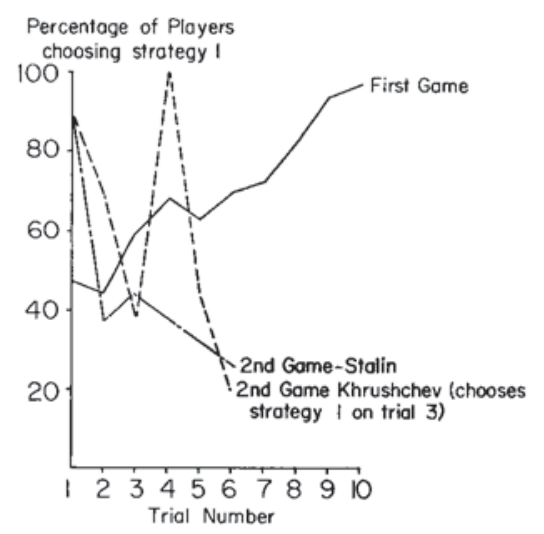

Frg. 4. Comparison of Behavior in First and Second Games (Matrix 3, Over 100 Trials).

fact, any player who ever initially doublecrossed Gandhi after co-operation was achieved eventually played only strategy 2 . The pattern fails at maximizing absolute payoffs, but even worse, fails at maximizing co-operation. Note that Figure 6 sharply differentiates between matrices 4 and 5 , thus showing the greater pull toward doublecrossing of the latter matrix.

\section{DISCUSSION}

We can pursue the three principal factors affecting co-operation in a slightly stronger context by restating the hypotheses to predict the achievemert of co-operation, rather than attempts at co-operation. The first factor would then predict that the amount of achieved co-operation would rise as the number of trials increases. Figure 7 presents the percentage of pairs co-operating at 1,1

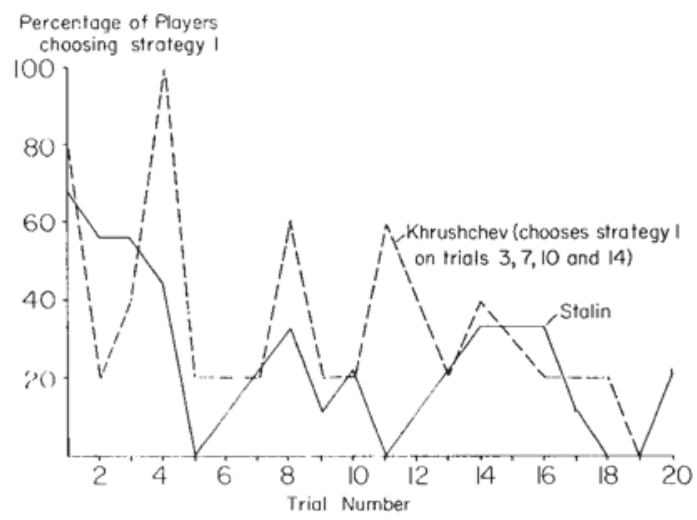

FIG. 5. Stalin vs. Khrushchev (Matrix 4, 50 Trials).

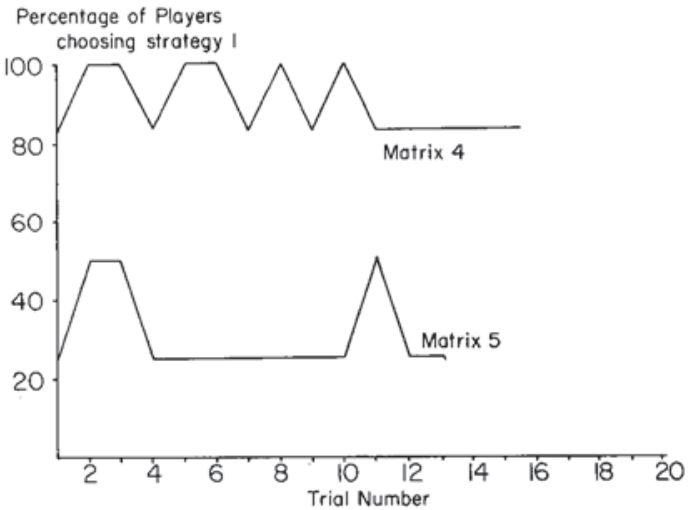

FIg. 6. Incentive to Double-Cross with a Gandhi Pattern (Matrices 4 and 5, 50 Trials).

in matrix 3 when the number of trials was changed successively from over 100 trials to 25 and then 15 . The amount of co-operation falls slightly in the reduction to 25 trials and then is reduced to zero in the 15trial games. Figure 8 presents the percentage of pairs co-operating in matrix 4 when the number of trials is reduced from over 100 to 50 and then to 15 . Figure 9 presents the percentage of pairs at 1,1 in matrix 5. These three figures generally support the hypothesis that the amount of achieved co-operation is directly related to the number of trials in the game.

For matrix 3 the percentage of pairs cooperating seems to bear an inverse relation to the number of trials; the shorter the game, the more co-operation is evidenced. A post hoc explanation of this tendency might

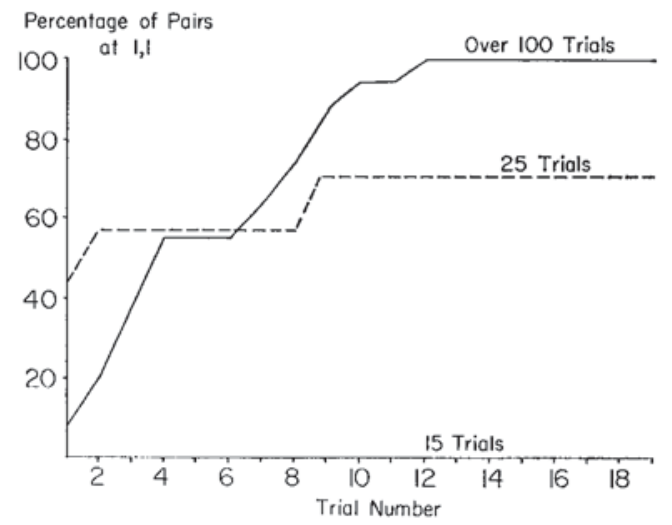

FIG. 7. Effect of Reducing the Number of Trials (Matrix 3, Over 100, 25, and 15 Trials). 


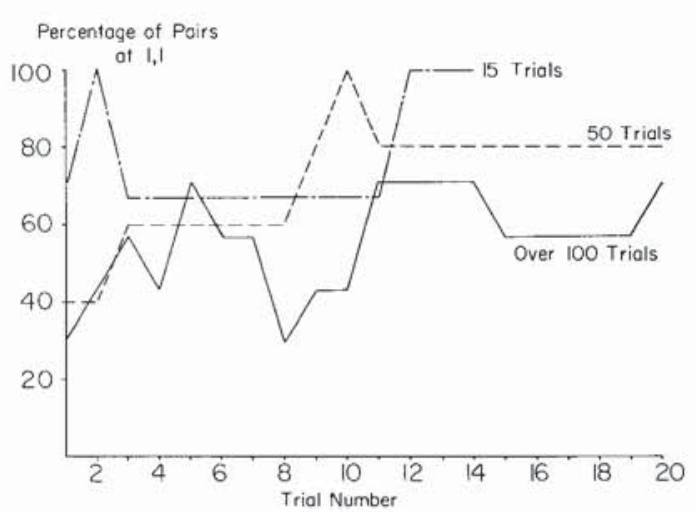

FIG. 8. Changes in Co-operation Due to Reducing the Number of Trials (Matrix 4, Over 100,50 , and 15 Trials).

point out that with shorter games there is less chance to mend any damage that might have been done by attempting to exploit a rival early in the game. Thus, the shorter the game, the less we might expect players to double-cross once they had achieved cooperation. However, the argument seems tenuous. Figure 8 contains no evidence for this hypothesis in matrix 4 , and there is no evidence from matrix 6 which would support the conclusion. It seems likely that all three curves in ligure 8 differ only by some random factor.

The second factor is transformed into hypotheses about the relationship between matrix entries and achieved co-operation. Figure 10 presents the percentage of players co-operating in matrices 1-4 in games with more than 100 trials. The first two matrices

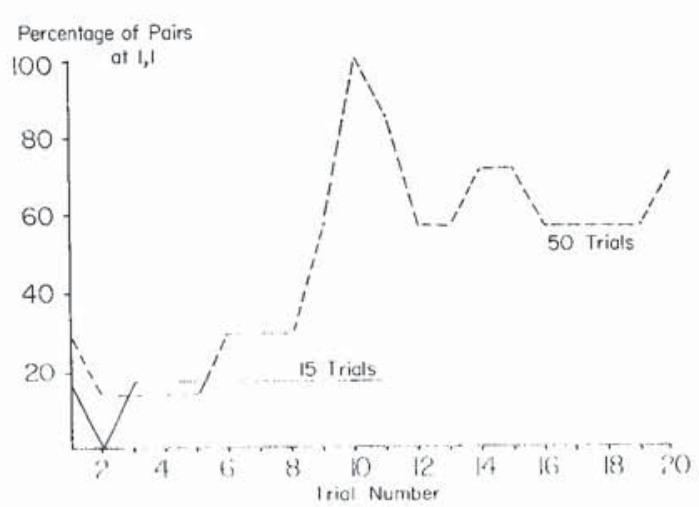

F16. 9. Effect of Reducing the Number of Trials (Matrix 5, 50 and 15 Trials).

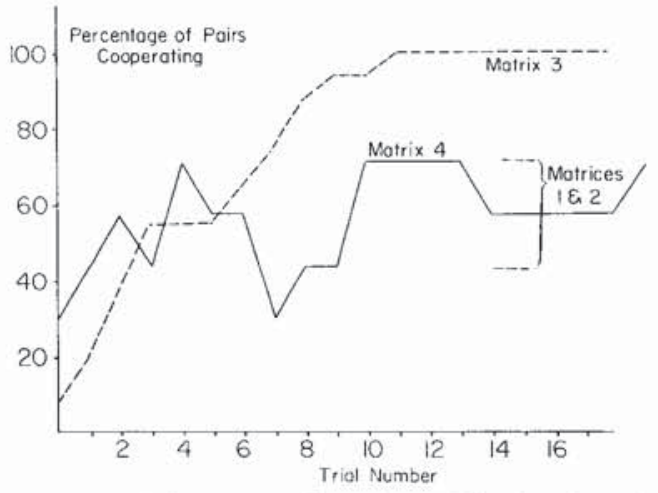

FIG. 10. Effect of Changing Matrix Entries (Matrices 1-2, 3, and 4, Over 100 Trials).

present some difficulty since they were used only with stooges and not with paired subjects. Given the difficulty of co-ordinating, it seems safe to assume that if two players were willing to play two or more strategy 1 's, they would have succeeded in co-operating. Since 11 of 14 subjects fit into this category, we might have expected five pairs to arrive at co-operation. Fven using the more strict criterion of three attempts at co-operation, only five players fail to qualify. Thus, it seems likely that between 43 and 71 per cent of the pairs would have arrived at co-operation in the first two matrices.

In matrix 3 all of the subjects arrived at stable co-operation. In matrix 4 only 70 per cent of the pairs colluded at any one time, and a smaller number must have arrived at stable co-opcration. On the other hand, every pair arrived at 1,1 at some time or other. Extending the hypothesis that more subjects would attempt co-operation as the magnitude of $b$ decreased to a hypothesis that the amount of stable co-operation would increase seems fraught with difficulties. The relation holds for the reduction of $b$ from $\$ 1$ to $\$ .50$, but fails in the further reduction to \$.05. The behavior might be explained by noting that with the large loss, subjects were reluctant to risk choosing strategy 1 initially. But, if they did risk it, they never deviated from cooperation once it had been attained. With the small-loss game, subjects were quite willing to risk indicating they wanted to co-operate, but had no good mechanism for 
enforeing co-operation once it had been temporarily attained. Thus, $b$ serves not only as a bar to co-operation as hypothesized, it serves as a means of enforcing co-operation.

Lawrence louraker suggests that matrices 1,2 , and 3 would not be Prisoner's Dilemmas if the entries were in utility rather than monetary terms. Certainly the utility of winning 4 cents is not going to be much greater than the utility of winning 3 cents. His point offers another explanation of why co-operation in these matrices was centered around the problem of attaining the cooperative point with no suggestion of moving away from $(1,1)$ once it was attained. On the other hand, co-operation in the other three matrices centered around the problem of staying at 1,1 .

It was conjectured that subjects would find this experiment a learning situation and behave quite differently in a second game. Measuring the difference is complicated here since the second game was not completely comparable to the first one. Players were paired in the first game and so reinforced their desire to arrive at a stable cooperative solution. The second game paired subjects with stooges who either chose no strategy 1's (Stalin) or chose only one strategy 1 (Khrushchev). Figure 4 presents a comparison of behavior in the two games. With Stalin or Khrushchev as a partner, it is inevitable that the number of attempts at co-operation must be biased downward and quickly fall to zero. The figure indicates that players in the second game were much more optimistic on the first trial; they demanded co-operation immediately. The number of strategy 1's they continued to play indicates they were willing to gamble much money on achieving co-operation. Thus, learning did oceur and players were reinforced by the first game.

These experiments provided a first test of differences between subjects since three universities in the Boston area provided the subjects for these experiments. Figure 11 presents the percentage of pairs from each university group co-operating in games using matrix :3 with more than 100 trials. Note that Harvard and M.I.T. subjects ex-

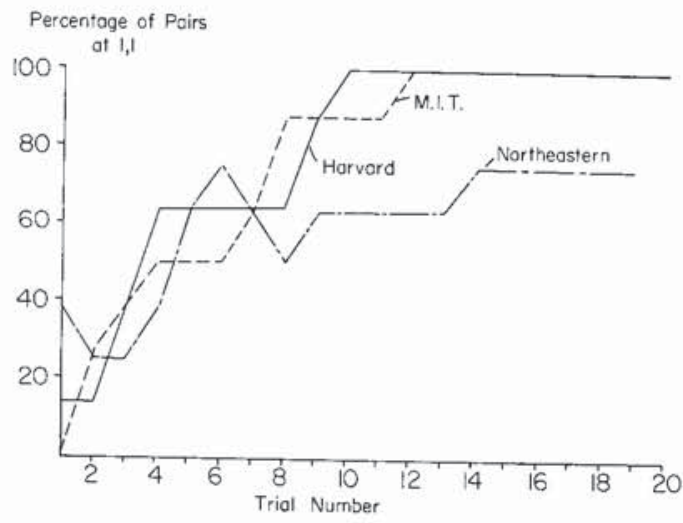

FI(i. 11. Comparison of Subjects from Three Universities (Matrix 3, Over 100 Trials).

hibit very similar behavior patterns while subjects from Northeastern University present quite a different picture. We did not attempt to investigate any of the many explanations that might account for this difference, but merely noted it and drew the conclusion that the Harvard and M.I.T. populations could be aggregated for the analysis.

In those games where less than 100 trials were to be played the subjects were told the exact number of trials in the game and so had the opportunity to end co-operation on the last trial or at some time before the end of the game. Table 4 lists the incidence of double-crossing in the paired games with specifically announced end points. The logic of the situation would have players never co-operating, since they would have decided to double-cross on the last trial and have extended the logic all the way back to the first trial. The table shows double-crossing to be concentrated in the last trial, although there are a few instances in earlier trials. Thus, the evidence agrees with previous experiments that double-crossing does not extend far back from the end of the game and that the process of backward induction is not nearly as powerful as the Luee-liaiffa $(1957)$ argunent might indicate.

The behavior exhibited toward Gandhi hinted that there is a period of feeling out a partner, of making sure that he has no obvious weakness. If weaknesses are found they will be exploited. This hypothesis can 
Lave, Lester B., Factors Affecting Co-operation in the Prisoner's Dilemma, Behavioral Science,

10:1 (1965:Jan.) p.26

Co-operation in the Prisoner's Dilemma

TABLE 4

Double-Crossing by Matrix

\begin{tabular}{|c|c|c|c|c|c|c|c|c|c|c|}
\hline $\begin{array}{l}\text { Matrix } \\
\text { Type }\end{array}$ & $\begin{array}{c}\text { Number } \\
\text { Trials }\end{array}$ & $\begin{array}{l}\text { Number } \\
\text { Subjects }\end{array}$ & $\begin{array}{l}\text { Number } \\
\text { at }(1,1)\end{array}$ & $\begin{array}{l}\text { I)ouble-( } \\
\text { Number }\end{array}$ & $\begin{array}{l}\text { Crossing: } \\
\text { Per Cent }\end{array}$ & On & $\begin{array}{c}\text { Dou } \\
\text { Last Trial }\end{array}$ & $\begin{array}{l}\text { able } \mathrm{C}_{1} \\
n-1\end{array}$ & sing: & $n-3$ \\
\hline 3 & 25 & 14 & 10 & 6 & 60 & & 6 & & & \\
\hline 4 & $\begin{array}{l}50 \\
15\end{array}$ & $\begin{array}{r}10 \\
6\end{array}$ & $\begin{array}{l}8 \\
6\end{array}$ & $\begin{array}{l}2 \\
3\end{array}$ & $\begin{array}{l}25 \\
50\end{array}$ & & $\begin{array}{l}2 \\
3\end{array}$ & & & \\
\hline 5 & $\begin{array}{l}50 \\
15\end{array}$ & $\begin{array}{r}14 \\
6\end{array}$ & $\begin{array}{l}9 \\
2\end{array}$ & $\begin{array}{l}5 \\
1\end{array}$ & $\begin{array}{l}56 \\
50\end{array}$ & & 3 & 1 & 1 & 1 \\
\hline
\end{tabular}

be tested by seeing whether, with some exceptions, co-operation is more likely to be stable if it is achieved only after some exploration of the possibilities. Figure 12 presents the number of non-1,1 choices before the first 1,1 choice and, on the other axis, the number of non-1,1 choices after the first 1,1 choice. The figure is dominated by two polar cases: first there are those pairs that took some time to reach 1,1 and then remained there; then there are those pairs that came to a 1,1 solution immediately and then deviated shortly afterwards. Only a few cases occur where the pairs reached immediate agreement and stayed there; these cases are rarer than might have been expected. It appears that easy victory is not always to be looked for.

Scodel (1962) reports a series of experiments where subjects attempted to maximize their relative payoffs rather than their absolute payoffs. Scodel hypothesized that

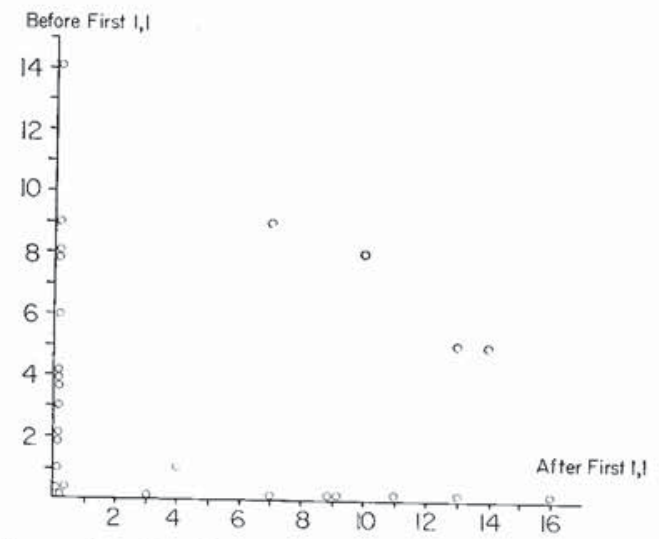

Frg. 12. Tradeoffs Between Nonco-operation Before and After First 1,1. such behavior would be general since it was observed in spite of efforts to find a matrix that would promote co-operation. Matrices 3 and 4 fit in with his definition and although there was some evidence that a low value of $b$ and a small number of iterations produced nonco-operative results essentially similar to Scodel's, there was no substantial evidence that players were maximizing any utility other than their own money payoff.

Throughout these experiments, subjects seemed to regard each other as equals and

TABLE 5

Test of Leadership Role

\begin{tabular}{|c|c|c|c|c|}
\hline Matrix & $\begin{array}{c}\text { Num- } \\
\text { ber } \\
\text { Trials }\end{array}$ & $\begin{array}{l}\text { Number } \\
\text { Pairs } \\
\text { Con- } \\
\text { sidered* }\end{array}$ & $\begin{array}{c}\text { Mean } \\
\text { Excess } \\
\text { Number } \\
\text { Strategy } 1 \\
\text { Choices } \\
\text { Made by } \\
\text { Leader } \dagger\end{array}$ & $\begin{array}{c}\text { Mean Excess } \\
\text { Number } \\
\text { Strategy } 1 \\
\text { Choices } \\
\text { Made by } \\
\text { Leader } \\
\text { Ignoring } \\
\text { Initial } \\
\text { Choice } \neq\end{array}$ \\
\hline 3 & 100 & 20 & .700 & -.300 \\
\hline 3 & 25 & 4 & +1.000 & 0 \\
\hline 3 & 15 & 3 & +2.000 & +1.000 \\
\hline 4 & 100 & 5 & +1.400 & +.400 \\
\hline 4 & 50 & 3 & +1.333 & +.333 \\
\hline 4 & 15 & 1 & +4.000 & +3.000 \\
\hline 5 & 50 & 5 & +.800 & -.200 \\
\hline
\end{tabular}

* Only those pairs are considered where one of the players chose strategy 1 before the other player, i.e., only those pairs where there was a leader.

$\dagger$ Derived by taking the difference between the total number of strategy 1's chosen by the follower and the number chosen by the leader and dividing by the number of pairs.

$\ddagger$ Previous column neglecting the initial trial in which the leader chose his first strategy 1. 
demanded at least equal payoffs. In the asymmetric game, for example, subjects insisted on at least equal payoffs though it cost them a great deal of money to do so. In all the paired games, subjects insisted on probing for possible weaknesses in their partners; and every time a weakness was discovered, it was exploited. One additional way of viewing this sort of behavior would be to look at the subject who first indicates that he wishes to co-operate by playing a strategy 1 . It is altogether possible that this subject will be taken advantage of and exploited continually, since he obviously has committed himself to co-operation. His opponent might occasionally double-cross once co-operation has been achieved, or be slow to learn to co-operate initially. Table 5 shows the difference in the number of strategy 1's played by the first subject who tried to signal co-operation and those played by his rival. Notice that, when we discount the initial attempt, the initial co-operator plays no more strategy 1's in general than his rival. Thus, again there is evidence that players insisted on equality and refused to allow themselves to be exploited.

\section{CONCLUSION}

The data were consistent with the hypothesis that subjects attempt co-operation when the number of trials is large enough that $3(b-d)<n(a-d)$. Subjects also attempt co-operation more often as $b$ is decreased from 100 to 5 and deviate from temporary co-operation as the $c$ is increased. The amount of achieved co-operation is a direct function of the number of trials and an inverse function of the size of $b$, although the latter relation is complicated by the dual role of $b$ since it also serves to enforce stable co-operation. Thus, the amount of co-operation decreases in the further reduction of $b$ from $\tilde{5} 0$ to $\tilde{5}$.

The fixed behavior patterns utilized as stooges in the game concentrated the information about subjects' reactions to certain strategies of interest. The Stalin pattern showed the reactions of subjects to cautious or malevolent partners. The Khrushchev pattern indicated that players will be greatly encouraged by the smallest sign that their previously cautious partner may wish to co-operate. Finally, the Gandhi pattern indicated that subjects engaged in rather costly searches for weaknesses in their rivals and, where a weakness was found, immediately exploited it.

Subjects tended to demand payoffs which were at least equal to those of their partners and generally double-crossed in the last few trials of the game, bargained so much that they generally failed to arrive at co-operation in the asymmetric matrix, and refused to take on a consistent role of leader in ensuring co-operation. The general behavior might be described as sharply competitive while still attempting to co-operate to the extent of earning a positive payoff.

\section{REFERENCES}

Berelson, B., \& Steiner, G. Human behavior; An inventory of scientific findings. New York: Harcourt, 1964.

Bishop, R. Duopoly: collusion or warfare? Amer. econ. Rev., 1960, 50, 933-967.

Deutsch, M. Co-operation and trust: some theoretical notes. In M. Jones (Ed.), Nebraska symposium on motivation. Lincoln: Univ. of Nebraska Press, 1962. Pp. 275-319.

Fouraker, L., \& Siegel, S. Bargaining behavior. New York: MeGraw-Hill, 1963.

Lave, L. Applications of the theory of games to economics. Unpublished A.B. dissertation, Reed College, 1960.

Lave, L. An empirical approach to the Prisoner's Dilemma. Quart. J. Econ., 1962, 76, 424-436.

Luce, R. D., \& Raiffa, H. Games and decisions. New York: Wiley, 1957.

Schelling, T. The strategy of conflict. Cambridge: Harvard Univ. Press, 1960.

Scodel, A. Induced collaboration in some nonzero-sum games. J. Conflict Resolution, 1962, 6, 334-340.

Siegel, S., \& Fouraker, L. Bargaining and group decision making. New York: McGraw-Hill, 1960.

Suppes, P., \& Carlsmith, J. Experimental analysis of a duopoly situation from the standpoint of mathematical learning theory. Internat. econ. Rev., 1962, 2, 60-78.

(Manuseript received July 29, 1963) 